M. Wallander - M. Bartnik - S. Efendic - A. Hamsten •

K. Malmberg · J. Öhrvik · L. Rydén · A. Silveira •

A. Norhammar

\title{
Beta cell dysfunction in patients with acute myocardial infarction but without previously known type 2 diabetes: a report from the GAMI study
}

Received: 15 June 2005 / Accepted: 28 June 2005 / Published online: 6 September 2005

(C) Springer-Verlag 2005

\begin{abstract}
Aims/hypothesis: Patients with acute myocardial infarction (AMI) but without previously known type 2 diabetes have a high prevalence of undiagnosed IGT and type 2 diabetes. Such perturbations have dismal prognostic implications. The aim of this study was to characterise AMI patients in terms of insulin resistance and beta cell function. Methods: A total of 168 consecutive AMI patients were classified by means of an OGTT before hospital discharge as having NGT, IGT or type 2 diabetes. The homeostasis model assessment (HOMA-IR) was used to estimate insulin resistance. Beta cell responsiveness was quantified as insulinogenic index (IGI) at $30 \min \left(\Delta \mathrm{I}_{30} / \Delta \mathrm{G}_{30}\right)$. Results: According to the HOMA-IR, patients with type 2 diabetes were more insulin resistant than those with IGT or NGT $(p=0.003)$. Beta cell responsiveness deteriorated with decreasing glucose tolerance as measured by the IGI (median [quartile 1, quartile 3] in pmol/mmol: NGT, 70.1 [42.7, 101.4]; IGT, 48.7 [34.7, 86.8], type 2 diabetes, 38.1 [25.7, 61.6]; $p<0.001$ ). The IGI was significantly related to admission capillary blood glucose $(r=-0.218, p=0.010)$
\end{abstract}

M. Wallander $(\bowtie) \cdot$ M. Bartnik $\cdot$ A. Hamsten $\cdot$ K. Malmberg

L. Rydén · A. Norhammar

Department of Cardiology, N5:00,

Karolinska University Hospital Solna,

17176 Stockholm, Sweden

e-mail: marit.wallander@medks.ki.se

Tel.: +46-709-419149

Fax: +46-834-4964

S. Efendic

Department of Endocrinology,

Karolinska University Hospital Solna,

Stockholm, Sweden

A. Hamsten · A. Silveira

Atherosclerosis Research Unit,

King Gustaf V Research Institute,

Karolinska University Hospital Solna,

Stockholm, Sweden

J. Öhrvik

Department of Epidemiology and Biostatistics,

Karolinska Institute,

Stockholm, Sweden and to the area under the curve for glucose $(r=-0.475$, $p<0.001)$. Conclusions/interpretation: Glucose abnormalities are very common in patients with AMI but without previously known type 2 diabetes. To a significant extent, this seems to be related to impaired beta cell function and implies that dysglycaemia immediately after an infarction is not a stress epiphenomenon but reflects stable disturbances of glucose regulation preceding the AMI. Early beta cell dysfunction may have important pathophysiological implications and may serve as a future target for treatment strategies.

Keywords Beta cell function - IGT - Impaired glucose tolerance $\cdot$ Insulinogenic index $\cdot$ Insulin resistance Myocardial infarction - Type 2 diabetes

Abbreviations AGT: abnormal glucose tolerance · AMI: acute myocardial infarction - AUCg: area under the curve for glucose · HOMA-IR: homeostasis model assessment of insulin sensitivity - hs-CRP: high-sensitivity C-reactive protein - IGI: insulinogenic index $\cdot$ WHO: World Health Organization

\section{Introduction}

During recent years it has become obvious that fasting plasma glucose is a continuous risk factor for future cardiovascular mortality and that the risk seems to start below the threshold for the diagnosis of diabetes [1]. However, classification by fasting glucose may miss patients with abnormal glucose tolerance, who also have less favourable cardiovascular risk profiles [2, 3]. In the GAMI (Glucose Tolerance in Patients with Acute Myocardial Infarction) study, OGTTs performed on patients without previously known type 2 diabetes but with an acute myocardial infarction (AMI) demonstrated that 35\% had impaired glucose tolerance (IGT) and $31 \%$ had previously undiagnosed type 2 diabetes [4]. Newly detected abnormal glucose tolerance (AGT; IGT or type 2 diabetes) was the strongest predictor of future cardiovascular events, together with previous myo- 
cardial infarction and stroke [5]. Type 2 diabetes is characterized by decreased insulin sensitivity and progressive beta cell dysfunction. The relative importance and causal relations of these disturbances in the pathogenesis of type 2 diabetes are under debate. Both insulin secretion and insulin sensitivity are genetically and environmentally controlled and the impairment of both, individually or together, has been associated with increased risk of developing type 2 diabetes [6-8]. It has been reported that, during each stage of the development of type 2 diabetes, decreased insulin sensitivity and insulin secretory dysfunction are independent predictors of worsening glucose tolerance [9]. Indeed, fasting hyperinsulinaemia, known to reflect decreased insulin sensitivity, and decreased insulin secretion together constitute the strongest independent predictor of type 2 diabetes [10]. Furthermore, decreased beta cell function may exist already at normal fasting plasma glucose levels [11]. Thus, detailed information on the pathogenesis of disturbed glucose regulation in AMI patients may pave the way for novel treatments aimed at improving cardiovascular outcome and delaying the onset of clinical diabetes and typical diabetes complications. The objective of the present report was to characterise patients with AMI and newly discovered AGT regarding their insulin resistance and beta cell function.

\section{Subjects and methods}

\section{Subjects}

A detailed description of the patients has been presented elsewhere [4, 5]. In brief, patients admitted for AMI were included if they fulfilled the following inclusion criteria: no previously known type 2 diabetes, baseline capillary blood glucose $<11.1 \mathrm{mmol} / \mathrm{l}$, serum creatinine $<200 \mu \mathrm{mol} / 1$ and age $\leq 80$ years. A total of 181 participants were enrolled, of whom 168 were characterised before hospital discharge by means of an OGTT as having either normal glucose tolerance (NGT), IGT or type 2 diabetes. The remaining 13 patients could not be classified because of conditions preventing an OGTT.

\section{Study protocol}

Blood glucose and creatinine were measured as soon as possible after arrival at the coronary care unit and $\mathrm{HbA}_{1 \mathrm{C}}$ on the first morning after admission. Fasting blood glucose was measured on the first morning after admission and repeated every morning until discharge. A standardized OGTT (75 g glucose in $200 \mathrm{ml}$ water) was performed on the day of hospital discharge (day 4 or 5), with capillary blood glucose measurements $0,15,30,60$ and $120 \mathrm{~min}$ after the glucose ingestion. Plasma concentrations of insulin and proinsulin were analysed in fasting samples taken on the first morning after admission and during the OGTT at 0,30 and $120 \mathrm{~min}$. Biochemical parameters, such as total cholesterol, HDL cholesterol, LDL cholesterol, triglycerides, high-sensitivity C-reactive protein (hs-CRP), cortisol, lipoprotein(a) and apolipoprotein B, were analysed in fasting samples taken on day 2 and at discharge. NEFA, plasminogen inhibitor activator-1 and fibrinogen were analysed in fasting samples taken at discharge. BMI was measured at admission. Three and 12 months after hospital discharge, the OGTT and all biochemical analyses were repeated, together with collection of clinical data. The present report relates to the glucometabolic classifications made before hospital discharge.

Type 2 diabetes and IGT were defined according to the 1998 World Health Organization (WHO) classification [12]. Thus, patients were considered as having type 2 diabetes if the fasting capillary blood glucose was $\geq 6.1$ and/ or 2-h capillary blood glucose $\geq 11.1 \mathrm{mmol} / \mathrm{l}$. IGT was diagnosed if fasting capillary blood glucose was $<6.1$ and 2-h capillary blood glucose $\geq 7.8$ but $<11.1 \mathrm{mmol} / \mathrm{l}$. NGT was defined as fasting capillary blood glucose $<6.1$ and 2-h capillary blood glucose $<7.8 \mathrm{mmol} / \mathrm{l}$. In the present report the term 'abnormal glucose tolerance' (AGT) is used for the presence of either IGT or type 2 diabetes. AMI was defined according to the joint recommendations of the European Society of Cardiology and the American College of Cardiology [13]. Thus, patients were diagnosed as having an AMI if they had two values of serum troponin $T>0.05 \mathrm{~g} / \mathrm{l}$ or creatine kinase-MB $>10 \mu \mathrm{g} / \mathrm{l}$ together with either typical symptoms (chest pain $>15$ min; pulmonary oedema in the absence of valvular heart disease; cardiogenic shock; arrhythmia such as ventricular fibrillation or ventricular tachycardia) or new Q-waves in at least two of the 12 standard ECG leads, or ECG changes indicating acute myocardial ischaemia (ST elevation, ST depression or T-wave inversion).

Insulin and proinsulin were quantified with enzyme immunoassays from Dako Diagnostics (Ely, UK). Intraand interassay coefficients of variation for these analyses were $6 \%$ and $7 \%$, respectively, for insulin and $5 \%$ and $6 \%$ for proinsulin. Details of biochemical analysis have been described elsewhere $[4,5,14]$.

\section{Calculations and statistical analysis}

The homeostasis model assessment of insulin resistance (HOMA-IR) was calculated in fasting conditions as plasma insulin $(\mathrm{pmol} / \mathrm{l}) \times$ blood glucose $(\mathrm{mmol} / \mathrm{l}) \times 1.13$ (correction for plasma glucose) $/ 22.5 \times 6$ (correction for $\mathrm{mU} / 1$ in original formula), as described by Matthews and colleagues [15]. An insulinogenic index (IGI) was calculated as the difference between the 30-min and 0-min OGTT plasma insulin values divided by the difference between the corresponding plasma glucose values, $\left(\Delta \mathrm{I}_{30} / \Delta \mathrm{G}_{30}\right)$, The proinsulin : insulin ratio was calculated as the ratio between the fasting values of proinsulin (pmol/l) and insulin (pmol/l). BMI was calculated as weight $/ \mathrm{height}^{2}\left(\mathrm{~kg} / \mathrm{m}^{2}\right)$. The area under the curve for glucose (AUCg) was calculated by numerical integration using Hermite polynomials [16]. Continuous variables are presented as medians (lower and upper quartile) and categorical variables as percentages. In the statistical analyses of the relations between various clinical and biochemical 
Table 1 Clinical characteristics of the patients at hospital discharge

${ }^{\mathrm{a}}$ Median (quartile 1, quartile 3)

\begin{tabular}{|c|c|c|c|c|}
\hline Variable & NGT $(n=55)$ & IGT $(n=58)$ & Type 2 diabetes mellitus $(n=55)$ & $p$ value \\
\hline \multicolumn{5}{|l|}{ Clinical characteristics } \\
\hline Age (years) & $60.0(54.0,67.0)^{\mathrm{a}}$ & $64.0(57.0,72.0)$ & $66.0(57.0,71.0)$ & 0.007 \\
\hline Sex (female, \%) & 20 & 29 & 36 & 0.058 \\
\hline Current smokers $(\%)$ & 40 & 38 & 27 & 0.163 \\
\hline BMI $\left(\mathrm{kg} / \mathrm{m}^{2}\right)$ & $26.0(23.1,28.3)$ & $26.6(23.1,29.7)$ & $27.0(24.2,29.7)$ & 0.143 \\
\hline \multicolumn{5}{|l|}{ Family history (\%) } \\
\hline Type 2 diabetes & 17 & 18 & 33 & 0.038 \\
\hline Coronary heart disease & 56 & 46 & 62 & 0.505 \\
\hline \multicolumn{5}{|l|}{ Previous disorders $(\%)$} \\
\hline Myocardial Infarction & 13 & 24 & 20 & 0.333 \\
\hline Angina pectoris & 31 & 33 & 31 & 1.000 \\
\hline Hypertension (treated) & 31 & 31 & 36 & 0.543 \\
\hline $\begin{array}{l}\text { Hyperlipidaemia } \\
\text { (treated) }\end{array}$ & 15 & 19 & 15 & 1.000 \\
\hline \multicolumn{5}{|l|}{$\begin{array}{l}\text { Treatment during } \\
\text { hospital stay } \\
\text { and discharge (\%) }\end{array}$} \\
\hline Thrombolysis & 45 & 28 & 42 & 0.696 \\
\hline Aspirin & 95 & 96 & 89 & 0.231 \\
\hline Beta-blockers & 93 & 93 & 91 & 0.681 \\
\hline ACE inhibitors & 16 & 12 & 17 & 0.939 \\
\hline Statins & 87 & 58 & 67 & 0.030 \\
\hline
\end{tabular}

parameters, only patients whose glucometabolic state was classified $(n=168)$ were included. Differences between patients grouped by glucose tolerance status were compared using the $\chi^{2}$ test, the Wilcoxon rank sum test or JonckheereTerpstra's test, the latter being a non-parametric test for ordered differences among classes. Pearson's correlation coefficients were calculated for pairs of continuous variables. Multiple regression analyses were performed with the admission capillary blood glucose and AUCg at discharge as dependent variables and HOMA-IR, IGI, age and sex as independent variables. Both HOMA-IR and IGI were $\log$-transformed prior to analysis. A two-sided $p$ value $<0.05$ was regarded as statistically significant. All analyses were performed using SAS version 9.1 (SAS Institute). The graphs were made using Statistica version 7.1 (StatSoft).
Table 2 Biochemical characteristics of the patients at hospital discharge

Values are median (quartile 1, quartile 3) PAI-1 plasminogen activator inhibitor 1

\begin{tabular}{|c|c|c|c|c|}
\hline Variable & NGT $(n=55)$ & IGT $(n=58)$ & $\begin{array}{l}\text { Type } 2 \text { diabetes } \\
\text { mellitus }(n=55)\end{array}$ & $p$ value \\
\hline $\begin{array}{l}\text { Admission capillary blood } \\
\text { glucose }(\mathrm{mmol} / \mathrm{l})\end{array}$ & $5.9(5.1,7.1)$ & $6.1(5.6,7.4)$ & $6.9(6.0,7.6)$ & $<0.001$ \\
\hline Fasting blood glucose $(\mathrm{mmol} / \mathrm{l})$ & $4.8(4.5,5.3)$ & $5.1(4.7,5.5)$ & $5.6(5.2,6.2)$ & $<0.001$ \\
\hline Blood glucose $120 \mathrm{~min}(\mathrm{mmol} / \mathrm{l})$ & $6.5(5.9,7.1)$ & $9.0(8.2,9.6)$ & $12.0(11.2,13.3)$ & $<0.001$ \\
\hline $\operatorname{AUCg}\left(\mathrm{mmol} \mathrm{l}^{-1} \mathrm{~min}^{-1}\right)$ & $927(854,1034)$ & $1119(1036,1213)$ & $1315(1204,1441)$ & $<0.001$ \\
\hline $\mathrm{HbA}_{1} \mathrm{c}(\%)$ & $4.8(4.5,5.2)$ & $4.9(4.5,5.2)$ & $5.1(4.6,5.5)$ & 0.023 \\
\hline hs-CRP (mg/l) & $12.7(5.3,28.0)$ & $18.8(8.7,57.6)$ & $29.2(14.1,80.4)$ & $<0.001$ \\
\hline \multicolumn{5}{|l|}{ Cholesterol (mmol/1) } \\
\hline Total & $5.5(4.6,6.0)$ & $5.0(4.5,5.7)$ & $5.1(4.3,5.8)$ & 0.161 \\
\hline HDL & $1.0(0.9,1.3)$ & $1.1(1.0,1.3)$ & $1.0(0.9,1.2)$ & 0.288 \\
\hline LDL & $3.3(2.6,3.9)$ & $3.0(2.5,3.6)$ & $3.1(2.4,3.8)$ & 0.296 \\
\hline Triglycerides (mmol/l) & $2.1(1.5,2.6)$ & $1.8(1.5,2.6)$ & $2.0(1.6,2.7)$ & 0.987 \\
\hline NEFA (mEq/l) & $0.39(0.30,0.61)$ & $0.54(0.35,0.69)$ & $0.59(0.39,0.78)$ & 0.005 \\
\hline Apolipoprotein B (g/l) & $1.1(0.9,1.3)$ & $1.0(0.9,1.2)$ & $1.0(0.8,1.2)$ & 0.344 \\
\hline PAI-1 activity (IU/ml) & $6.4(3.1,14.4)$ & $9.1(3.1,18.7)$ & $11.7(4.6,22.8)$ & 0.054 \\
\hline Fibrinogen $(\mathrm{g} / \mathrm{l})$ & $5.1(4.3,6.3)$ & $5.2(4.6,6.5)$ & $5.6(4.2,8.5)$ & 0.114 \\
\hline Cortisol (nmol/1) & $486(408,609)$ & $473(399,540)$ & $491(390,621)$ & 0.729 \\
\hline S-Creatinine $(\mu \mathrm{mol} / \mathrm{l})$ & $92(82,100)$ & $92(81,104)$ & $89(77,100)$ & 0.296 \\
\hline Lipoprotein(a) (g/l) & $0.16(0.06,0.39)$ & $0.19(0.07,0.41)$ & $0.21(0.06,0.44)$ & 0.468 \\
\hline
\end{tabular}


Table 3 Insulin resistance and beta cell function at the time of hospital discharge and at 3 and 12 months

\begin{tabular}{|c|c|c|c|c|}
\hline Variable & NGT & IGT & Type 2 diabetes mellitus & $p$ value \\
\hline Discharge & $(n=55)$ & $(n=58)$ & $(n=55)$ & \\
\hline Blood glucose $30 \mathrm{~min}(\mathrm{mmol} / \mathrm{l})$ & $8.7(7.7,9.6)$ & $9.1(8.4,10.2)$ & $9.8(9.0,10.9)$ & $<0.001$ \\
\hline Insulin baseline (pmol/l) & $52(33,70)$ & $53(34,78)$ & $60(43,101)$ & 0.046 \\
\hline Insulin $30 \mathrm{~min}(\mathrm{pmol} / \mathrm{l})$ & $328(217,404)$ & $313(195,430)$ & $267(185,370)$ & 0.079 \\
\hline Insulin $120 \min (\mathrm{pmol} / \mathrm{l})$ & $236(132,371)$ & $489(321,704)$ & $574(370,1080)$ & $<0.001$ \\
\hline Proinsulin baseline (pmol/1) & $4.9(3.9,6.8)$ & $6.2(4.6,9.1)$ & $7.4(5.0,10.5)$ & $<0.001$ \\
\hline HOMA-IR (mU mmol $\left.{ }^{-1} 1^{-1}\right)$ & $2.07(1.34,2.71)$ & $2.13(1.49,3.67)$ & $2.91(1.69,4.70)$ & 0.003 \\
\hline Insulinogenic index ${ }^{a}$ & $70.1(42.7,101.4)$ & $48.7(34.7,86.8)$ & $38.1(25.7,61.6)$ & $<0.001$ \\
\hline Proinsulin : insulin ratio & $0.10(0.09,0.14)$ & $0.12(0.08,0.17)$ & $0.12(0.08,0.17)$ & 0.140 \\
\hline 3 months & $(n=48)$ & $(n=47)$ & $(n=47)$ & \\
\hline HOMA-IR (mU mmol $\left.{ }^{-1} 1^{-1}\right)$ & $2.14(1.63,3.01)$ & $2.25(1.57,3.18)$ & $3.54(1.88,5.18)$ & 0.007 \\
\hline Insulinogenic index ${ }^{a}$ & $44.5(32.9,70.6)$ & $47.7(35.6,64.2)$ & $37.2(20.6,57.5)$ & 0.016 \\
\hline Proinsulin : insulin ratio & $0.09(0.07,0.14)$ & $0.12(0.09,0.16)$ & $0.13(0.09,0.18)$ & 0.037 \\
\hline 12 months & $(n=44)$ & $(n=38)$ & $(n=42)$ & \\
\hline HOMA-IR (mU mmol $\left.{ }^{-1} 1^{-1}\right)$ & $2.61(1.54,3.42)$ & $2.87(1.65,5.06)$ & $4.15(2.09,6.89)$ & $<0.001$ \\
\hline Insulinogenic index ${ }^{\mathrm{a}}$ & $50.0(33.9,99.0)$ & $52.7(32.8,77.9)$ & $38.3(24.1,58.9)$ & 0.048 \\
\hline Proinsulin : insulin ratio & $0.06(0.04,0.12)$ & $0.07(0.05,0.10)$ & $0.08(0.06,0.13)$ & 0.121 \\
\hline
\end{tabular}

Classifications of the three groups are all based on OGTT data obtained at the time of discharge. Values are median (quartile 1, quartile 3) ${ }^{\mathrm{a}} \Delta 30 \mathrm{I} / \Delta 30 \mathrm{G}(\mathrm{pmol} / \mathrm{mmol})$

\section{Ethical considerations}

The study was approved by the regional ethics committee at Karolinska Institute, and all patients provided written and oral informed consent.

\section{Results}

Glycaemic control and biochemical characteristics

At hospital discharge $33 \%(n=55)$ of the patients were classified as having NGT while $35 \%(n=58)$ had IGT and $33 \%(n=55)$ newly detected type 2 diabetes. Clinical characteristics of these three groups are presented in Table 1. Patients with IGT and type 2 diabetes were older than those with NGT and a family history of type 2 diabetes was more common among patients with type 2 diabetes. The three groups were similar regarding most other clinical data, such as BMI, sex, smoking and previous disorders. Medical treatment during hospital stay and discharge, including thrombolysis, aspirin, beta-blockers and ACE inhibitors, was similarly distributed among the groups except for statins, which were more often prescribed to patients in the NGT group. The biochemical characteristics at discharge are presented in Table 2. The variables that differed between the groups were admission capillary blood glucose, fasting blood glucose, 120-min blood glucose, $\mathrm{HbA}_{1 \mathrm{C}}$, AUCg, hs-CRP and NEFA, all of which were higher in the IGT and type 2 diabetes groups.
Insulin resistance and beta cell function

All parameters related to insulin resistance and beta cell function at discharge are presented in Table 3. Abnormal glucose tolerance was associated with increasing insulin resistance as measured by the HOMA-IR $\left(\mathrm{mU} \mathrm{mmol}^{-1} \mathrm{l}^{-1}\right)$. Fasting insulin increased in the groups with AGT whereas the 30-min insulin levels showed a borderline significant

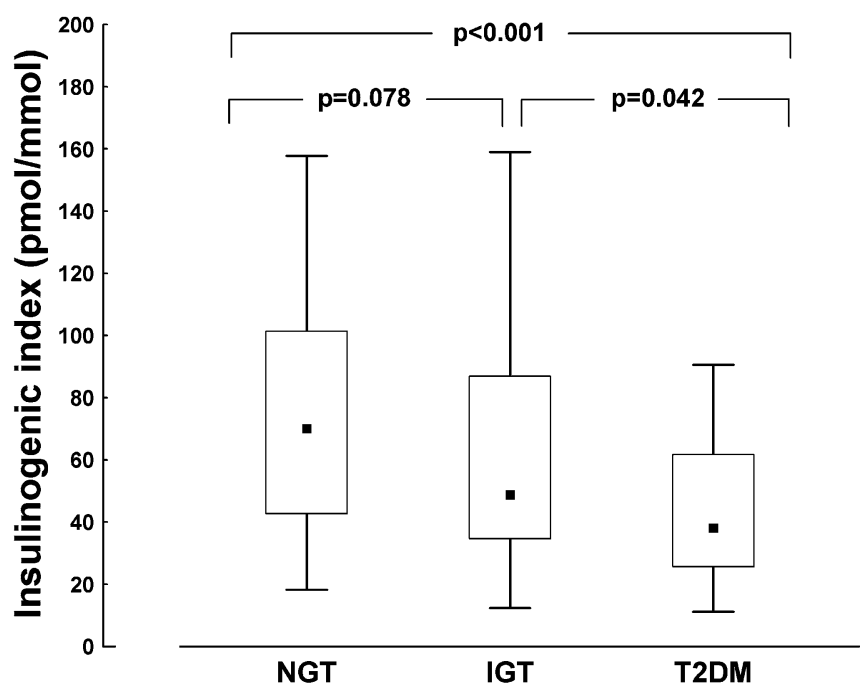

Fig. 1 Beta cell function quantified as insulinogenic index in patients with NGT $(n=55)$, IGT $(n=58)$ and type 2 diabetes mellitus (T2DM, $n=55$ ). Box plots display median, interquartile range and non-outlier range. Extreme values are excluded from the box plots 


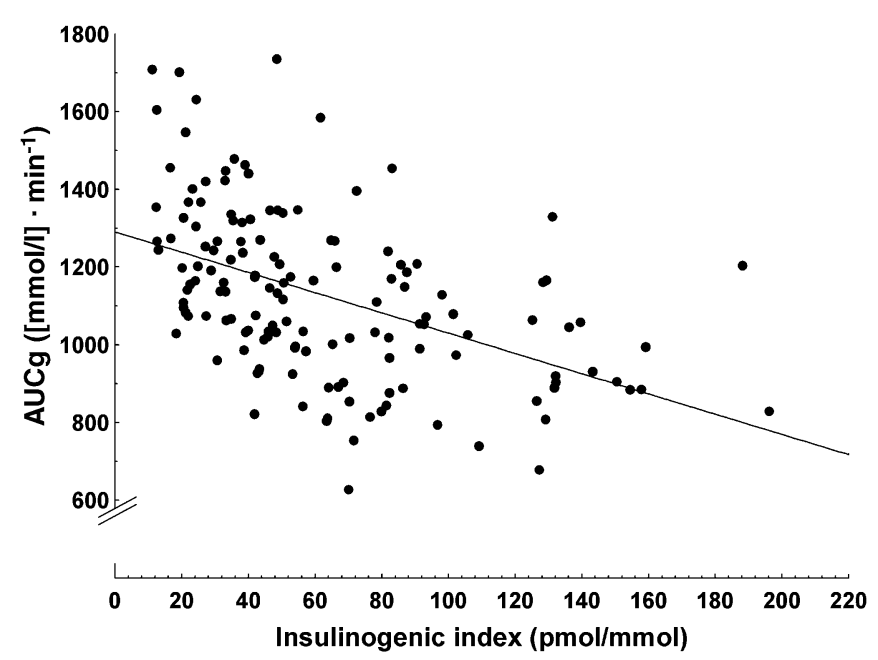

Fig. 2 Relationship at discharge between the AUCg and the insulinogenic index in all patients. $r=-0.475, p<0.001$

decrease $(p=0.079)$ and the 120-min insulin levels were significantly increased in patients with AGT. Baseline levels of proinsulin were significantly increased in patients with AGT, but this was not the case with the proinsulin : insulin ratio $(p=0.140)$. The IGI was significantly lower in patients with type 2 diabetes compared with patients with IGT or NGT $(p<0.001$; Fig. 1). Analyses of insulin resistance and beta cell function were repeated 3 and 12 months after hospital discharge. On these occasions approximately $20 \%$ and $30 \%$ of the patients had been lost to follow-up due to deaths and logistic problems, respectively, which were similarly distributed between the three groups. When comparing the glucometabolic groups classified at discharge, the pattern of increased insulin resistance and decreased beta cell function among patients with AGT persisted at 3 and 12 months (Table 3 ).

The IGI at discharge was significantly related to admission capillary blood glucose $(r=-0.218, p=0.010)$. After performing a multiple regression analysis with admission capillary blood glucose as the dependent variable and IGI, HOMA-IR, age and sex as the independent variables, IGI and HOMA-IR remained independent predictors $\left(r^{2}=0.065\right.$, $p=0.002$ and $r^{2}=0.028, p=0.039$ respectively).

There was a strong negative correlation between the IGI and AUCg in all patients at discharge $(r=-0.475 ; p<0.001$;

Table 4 Multiple linear regression analysis with the AUCg at discharge as the dependent variable

\begin{tabular}{lcrr}
\hline Variable & Partial $R^{2}$ & $\begin{array}{l}\text { Parameter } \\
\text { estimate }\end{array}$ & $p$ value \\
\hline Insulinogenic index $^{\mathrm{a}}$ & 0.286 & -177.6 & $<0.001$ \\
HOMA-IR (mU mmol $\left.^{-1} \mathrm{l}^{-1}\right)$ & 0.155 & 138.8 & $<0.001$ \\
Sex (female=1) & 0.048 & 96.5 & $<0.001$ \\
Age (year) & 0.022 & 3.5 & 0.013 \\
\hline
\end{tabular}

All continuous variables were log-transformed before analysis. Adjusted $R^{2}$ for the model was $49.7 \%$

a $\Delta 30 \mathrm{I} / \Delta 30 \mathrm{G}(\mathrm{pmol} / \mathrm{mmol})$
Fig. 2). When performing a multiple regression analysis using AUCg at discharge as the dependent variable and HOMA-IR, IGI, age and sex as independent variables, IGI explained more of the variability in $\operatorname{AUCg}\left(r^{2}=0.286\right.$; $p<0.001)$ than HOMA-IR $\left(r^{2}=0.155, p<0.001\right.$; Table 4$)$.

\section{Discussion}

The main finding in this study was that, to a significant extent, the glucose abnormalities that are very common in postinfarction patients are due to decreased early-phase beta cell secretion of insulin.

The high prevalence of IGT (35\%) and newly diagnosed type 2 diabetes (31\%) in patients with AMI previously reported from this study [4] was recently confirmed by the Euro Heart Survey [17]. In this survey a majority of patients with manifest coronary heart disease had AGT. The need for an OGTT to correctly diagnose these patients was also underlined. The superiority of OGTT over fasting glucose only was confirmed by another study in which diabetes was diagnosed by means of fasting glucose in $10 \%$ of patients with myocardial infarction. By applying the $\mathrm{WHO}$ criteria, which are based on OGTT, this figure was increased to $33 \%$ [18].

Evidence has accumulated during the last decade on the significant roles of both decreased insulin sensitivity and beta cell dysfunction in the pathogenesis of type 2 diabetes. In previous analyses of the present patient material, we have seen that patients with AMI and AGT did not differ as much as would have been expected in insulin resistance compared with patients with NGT and compared with controls. Furthermore, large differences in proinsulin between patients and controls were found [14]. Therefore, we wanted to further investigate the pathogenesis of AGT by estimating beta cell function in this specific patient group. Although disturbed glucose regulation is a common characteristic of patients with AMI, specific attention has not, until very recently [19], been devoted to beta cell dysfunction in these patients.

During recent years, several indices of insulin sensitivity derived from the OGTT have been developed, such as those suggested by Stumvoll and colleagues [20] and by Mari and colleagues [21]. These indices have the advantage of giving information similar to that obtained with the clamp technique [22]. The present sampling frequency during the OGTT did not, however, permit calculations according to these models. As an alternative we used HOMA-IR as a simple and reasonably adequate estimation of insulin resistance. This index, which has been used in many large population studies, correlates well with other, more complex techniques $[23,24]$. Simple indices of beta cell secretion have also been developed over the years. The homeostasis model assessment for insulin secretion (HOMA-\%B) [15] has been criticised as too insensitive since it does not reflect the early insulin response and it cannot be validated in patients on glucose-lowering drugs. In this study, we estimated beta cell function by means of the IGI $30 \mathrm{~min}$ after oral glucose intake $(\Delta \mathrm{I} 30 / \Delta \mathrm{G} 30)$, corresponding to the early insulin response to oral glucose stimulation. The IGI is a 
commonly used index of beta cell secretion and has been used in multiple studies to measure the early-phase beta cell response to a glucose stimulus [25-28]. In comparative studies of several indices of beta cell function, the IGI index was closely correlated with insulin secretion [29].

Recent studies have presented results that indicate that beta cell dysfunction in early stages of AGT is present independently of insulin resistance and is already present in obese patients with NGT [30-32]. In addition, a study of type 2 diabetic Japanese patients recently showed that decreased insulin secretion had a more pronounced impact on glucose tolerance than insulin sensitivity [33]. The relationships of insulin resistance and beta cell function to the response to the OGTT were also investigated in the present study by comparing the respective contributions of HOMAIR and IGI to AUCg. There were strong correlations between both measures and AUCg, but beta cell dysfunction was a significantly stronger contributor than increasing insulin resistance. This further underlines the importance of beta cell dysfunction as a contributor to AGT in patients with AMI.

Both glucose toxicity and lipotoxicity have been reported to contribute to beta cell dysfunction. The lipotoxicity has above all been associated with elevated plasma NEFA concentrations, which have been observed to hamper insulin secretion through toxic effects on the beta cells [34, 35]. Furthermore, long-term lowering of plasma NEFA improves the acute insulin response and insulin-mediated glucose uptake [36]. In the present study, concentrations of NEFA were significantly increased in patients with AGT and may therefore have contributed to the beta cell dysfunction.

A limitation of the present study was that we were not able to control for the influence of intestinal hormones on beta cell function. Since insulin secretion is increased by incretins after oral glucose ingestion, the possibility that these hormones affect beta cell secretion must be taken into consideration [37].

Moreover, and as could be expected, concentrations of hs-CRP were significantly increased in patients with AGT. There were no significant relationships between hs-CRP and parameters of insulin resistance or beta cell dysfunction.

Another interesting finding in the present study was that fasting values of proinsulin and the proinsulin : insulin ratio, associated with beta cell dysfunction [38], tended to increase in patients with abnormal compared with those with normal glucose tolerance. It was recently reported that the proinsulin : insulin ratio and the acute insulin response were independent predictors of type 2 diabetes. Individuals with a combination of a low acute insulin response and a high proinsulin : insulin ratio were at the highest risk of developing type 2 diabetes [39]. Furthermore, in a recent Swedish study proinsulin predicted cardiovascular death and morbidity over a period of 27 years, independently of other major cardiovascular risk factors [40].

The observed disturbances, of increased beta cell dysfunction and insulin resistance, in patients with AGT persisted 3 and 12 months after hospital discharge. During this period none of the patients was treated with any oral glucose-lowering drug or insulin.
In conclusion, this study shows that glucose abnormalities in patients with AMI but without previously known type 2 diabetes are to a significant extent related to impaired beta cell secretion of insulin. This confirms that hyperglycaemia immediately after an infarction is not mainly a stress epiphenomenon, as commonly assumed, but reflects a stable disturbance of glucose regulation preceding the AMI. Early beta cell dysfunction in this specific patient group may have important pathophysiological implications. Moreover, the present findings should have therapeutic implications when choosing pharmacological tools in future attempts to improve the glucometabolic state, and hopefully also in the prognosis of patients with abnormal glucose metabolism in connection with myocardial infarction.

Acknowledgements This study was supported by AFA Insurance, the Swedish Heart-Lung Foundation, King Gustaf V and Queen Victoria Foundation and Aventis Pharma. These grants, obtained in competition, were totally unrestricted and unconditional. The authors are grateful to C. Hage and M.-L. Ojutkangas for excellent care of patients and control subjects; A. Larsson for performing laboratory analyses; and K. Danell-Toverud for handling the samples.

\section{References}

1. Coutinho M, Gerstein HC, Wang Y, Yusuf S (1999) The relationship between glucose and incident cardiovascular events: a meta-regression analysis of published data from 20 studies of 95,783 individuals followed for 12.4 years. Diabetes Care 22: 233-240

2. The DECODE Study Group (1999) Glucose tolerance and mortality comparison of WHO and American Diabetes Association diagnostic criteria. Lancet 35:1617-1621

3. Liao D, Shofer JB, Boyko EJ et al (2001) Abnormal glucose tolerance and increased risk for cardiovascular disease in Japanese-Americans with normal fasting glucose. Diabetes Care 24:39-44

4. Norhammar A, Tenerz A, Nilsson G et al (2002) Glucose metabolism in patients with acute myocardial infarction and no previous diagnosis of diabetes mellitus: a prospective study. Lancet 359:2140-2144

5. Bartnik M, Malmberg K, Norhammar A, Tenerz, Ohrvik J, Ryden L (2004) Newly detected abnormal glucose tolerance: an important predictor of long-term outcome after myocardial infarction. Eur Heart J 25:1990-1997

6. Pimenta W, Korytkowski M, Mitrakou A et al (1995) Pancreatic beta-cell dysfunction as the primary genetic lesion in NIDDM. JAMA 273:1855-1861

7. Polonsky KS, Sturis J, Bell GI (1996) Seminars in Medicine of the Beth Israel Hospital, Boston. Non-insulin-dependent diabetes mellitus - a genetically programmed failure of the beta cell to compensate for insulin resistance. N Engl J Med 334:777-783

8. Weyer C, Bogardus C, Mott DM, Pratley RE (1999) The natural history of insulin secretory dysfunction and insulin resistance in the pathogenesis of type 2 diabetes mellitus. J Clin Invest 104:787-794

9. Weyer C, Tataranni PA, Bogardus C, Pratley RE (2001) Insulin resistance and insulin secretory dysfunction are independent predictors of worsening of glucose tolerance during each stage of type 2 diabetes development. Diabetes Care 24:89-94

10. Haffner SM, Miettinen H, Stern MP (1997) Are risk factors for conversion to NIDDM similar in high and low risk populations? Diabetologia 40:62-66

11. Godsland IF, Jeffs JA, Johnston DG (2004) Loss of beta-cell function as fasting glucose increases in the non-diabetic range. Diabetologia 47:1157-1166 
12. Alberti KGMM, Zimmet P, for the WHO consultation (1998) Definition, diagnosis and classification of diabetes mellitus and its complications, part 1: diagnosis and classification of diabetes mellitus - provisional report of a WHO consultation. Diabet Med 15:539-553

13. Anon (2000) Myocardial infarction redefined: a consensus document of the Joint European Society of Cardiology/American College of Cardiology Committee for the redefinition of myocardial infarction. Eur Heart J 21:1502-1513

14. Bartnik M, Malmberg K, Hamsten A et al (2004) Abnormal glucose tolerance - a common risk factor in patients with acute myocardial infarction in comparison with population-based controls. J Intern Med 256:288-297

15. Matthews DR, Hosker JP, Rudenski AS, Naylor BA, Treacher DF, Turner RC (1985) Homeostasis model assessment: insulin resistance and beta-cell function from fasting plasma glucose and insulin concentrations in man. Diabetologia 28:412-419

16. Abramowitz M, Stegun IA (1972) Handbook of mathematical functions. Dover, New York

17. Bartnik M, Ryden L, Ferrari R, et al on behalf of the Euro Heart Survey Investigators (2004) The prevalence of abnormal glucose regulation in patients with coronary artery disease across Europe. The Euro Heart Survey on diabetes and the heart. Eur Heart J 25:1880-1890

18. Choi KM, Lee KW, Kim SG et al (2005) Inflammation, insulin resistance, and glucose intolerance in acute myocardial infarction patients without a previous diagnosis of diabetes mellitus. J Clin Endocrinol Metab 90:175-180

19. Hashimoto K, Ikewaki K, Yagi H et al (2005) Glucose intolerance is common in Japanese patients with acute coronary syndrome who were not previously diagnosed with diabetes. Diabetes Care 28:1182-1186

20. Stumvoll M, Mitrakou A, Pimenta W et al (2000) Use of the oral glucose tolerance test to assess insulin release and insulin sensitivity. Diabetes Care 23:295-301

21. Mari A, Pacini G, Murphy E, Ludvik B, Nolan JJ (2001) A model-based method for assessing insulin sensitivity from the oral glucose tolerance test. Diabetes Care 24:539-548

22. Mari A, Pacini G, Brazzale AR, Ahren B (2005) Comparative evaluation of simple insulin sensitivity methods based on the oral glucose tolerance test. Diabetologia 48:748-751

23. UK Prospective Diabetes Study Group (1995) UKPDS 16. Overview of 6 years' therapy of type II diabetes: a progressive disease. Diabetes 44:1249-1258

24. Howard G, Bergman R, Wagenknecht LE et al (1998) Ability of alternative indices of insulin sensitivity to predict cardiovascular risk: comparison with the 'minimal model'. Insulin Resistance Atherosclerosis Study (IRAS) Investigators. Ann Epidemiol 8:358-369

25. Pimenta WP, Rudge MVC, Aragon FF, Padovani CR (2004) Pancreatic beta-cell defects in women at risk of type 2 diabetes. Diabetes Res Clin Pract 63:87-92

26. Haffner SM, Miettinen H, Gaskill SP, Stern MP (1995) Decreased insulin secretion and increased insulin resistance are independently related to the 7-year risk of NIDDM in Mexican-Americans. Diabetes 44:1386-1391
27. Viberti, G, Kahn SE, Greene DA et al (2002) A diabetes outcome progression trial (ADOPT). Diabetes Care 25:1737-1743

28. Tripathy D, Carlsson AL, Lehto M, Isomaa B, Tuomi T, Groop L (2000) Insulin secretion and insulin sensitivity in diabetic subgroups: studies in the prediabetic and diabetic state. Diabetologia 43:1476-1483

29. Taniguchi A, Nagasaka S, Fukushima M et al (2000) Assessment of insulin sensitivity and insulin secretion from the oral glucose tolerance test in nonobese Japanese type 2 diabetic patients: comparison with minimal-model approach. Diabetes Care 23:1439-1440

30. Pratley RE, Weyer C (2001) The role of impaired early insulin secretion in the pathogenesis of Type II diabetes mellitus. Diabetologia 44:929-945

31. Ferrannini E, Gastaldelli A, Miyazaki Y, Matsuda M, Mari A, Defronzo RA (2005) Beta-cell function in subjects spanning the range from normal glucose tolerance to overt diabetes: a new analysis. J Clin Endocrinol Metab 90:493-500

32. Yeckel CW, Taksali SE, Dziura J et al (2005) The normal glucose tolerance continuum in obese youth: evidence for impairment in beta-cell function independent of insulin resistance. J Clin Endocrinol Metab 90:747-754

33. Fukushima M, Suzuki H, Seino Y (2004) Insulin secretion capacity in the development from normal glucose tolerance to type 2 diabetes. Diabetes Res Clin Pract 66(Suppl):S37-S43

34. Yki-Jarvinen H (1992) Glucose toxicity. Endocr Rev 13:415431

35. Boden G, Shulman GI (2002) Free fatty acids in obesity and type 2 diabetes: defining their role in the development of insulin resistance and $\beta$-cell dysfunction. Eur J Clin Invest 32: $14-23$

36. Paolisso G, Tagliamonte MR, Rizzo MR et al (1998) Lowering fatty acids potentiates acute insulin response in first degree relatives of people with type II diabetes. Diabetologia 41:11271132

37. Creutzfeldt W, Nauck M (1992) Gut hormones and diabetes mellitus. Diabetes Metab Rev 8:149-177

38. Roder ME, Porte D Jr, Schwartz RS, Kahn SE (1998) Disproportionately elevated proinsulin levels reflect the degree of impaired B cell secretory capacity in patients with noninsulin-dependent diabetes mellitus. J Clin Endocrinol Metab 83:604-608

39. Hanley AJ, D'Agostino R Jr, Wagenknecht LE et al (2002) Increased proinsulin levels and decreased acute insulin response independently predict the incidence of type 2 diabetes in the insulin resistance atherosclerosis study. Diabetes 51:12631270

40. Zethelius B, Byberg L, Hales CN, Lithell H, Berne C (2002) Proinsulin is an independent predictor of coronary heart disease: report from a 27 -year follow-up study. Circulation 105 : $2153-2158$ 